\title{
Anatomical Variation of the Common Carotid Artery in neck Dissection- Cervical carotid siphon
}

\author{
${ }^{1}$ Dr. AmruthaRoopa Ramagalla, ${ }^{2}$ Dr. Pulluri Sadanandam, \\ ${ }^{3}$ Dr. Takkallapally Anitha \\ ${ }^{1 \& 3}$ Department of Anatomy, Chalmeda Ananda Rao Institute of Medical sciences, Karimnagar, \\ Telangana, India. \\ ${ }^{2}$ Department of Community Medicine, Chalmeda Ananda Rao Institute of Medical sciences, Karimnagar, \\ Telangana, India
}

\begin{abstract}
Knowledge of incidence of morphological variations in the course and branching of the carotid arteries is important for radiological interpretation and surgical correction when they are symptomatic. Internal carotid artery (ICA) is known to show elongation in its extra cranial course. Previous studies have demonstrated the incidence and clinical symptoms of this morphological entity. However, the occurrence of elongation and looping of the common carotid artery (CCA) is seldom reported in the literature. During regular dissections, we came across a rare case of unilateral morphological variation of common carotid artery, in a female cadaver aged about 55 years. CCA presented a pronounced kinking or coiling, $2 \mathrm{~cm}$ above the origin of CCA.
\end{abstract}

Keywords: Common Carotid Artery (CCA and Siphon)

\section{Introduction}

Common carotid arteries chiefly supply the head and neck region. Each common carotid artery bifurcates into external carotid artery (ECA) and internal carotid artery (ICA). According to classical text book description, the carotid arteries run straight in the neck region (1). Rarely, they show coiling in their course (2). Compared to ECA, ICA more frequently presents such morphological entity (3). Usually, ICA begins at the level of the lamina of the upper border of the thyroid cartilage and enters into the temporal bone. If the distance between these two points is lesser than the vessel length, it leads to coiling, looping and kinking of the vessel (4). However, these conditions are thought to occur due to the benign angiopathy (5) or neurological complications (6) or also considered as congenital anomalies (3). The knowledge of morphological variants of carotid arteries is important while performing procedures such as tonsillectomy, peritonsillar abscess drainage, soft palate impalement injuries, adenoidectomy and velopharyngeoplasty (3). Herein, we report a unilateral variation of both the ECA and ICA in the neck region, and discuss its clinical importance.

\section{Meterial and methods}

23 in the right and 23 in the left side, of formol-fixed adult cadavers, of both sexes were dissected from the chalmeda anand rao medical college, karimnagar from 2013 - 2016. We came across a rare unilateral morphological variation in the course of the common carotid arteri in asigle female cadaver of aged approximately 55 years. The variation was observed on the left side of the neck and was unilateral.

\section{Discussion}

Classically, the carotid arterial system presents constant origin and course in the superior mediastinum and neck (1). When compared to CCA and ECA, ICA frequently shows variations in its course and forms coiling, looping and kinking or tortuosity (3). In 1951, Riser et al (7) have demonstrated the association between the carotid kinking and cerebrovascular insufficiency. Variations of ICA are could be due to developmental errors of aortic arteries (3) as looping and kinking is also reported to occur in the infants and fetuses (8). During the ICA development, usually major portions of segmental arteries that contribute to its formation disappear. Rarely they may persist and give rise to the anomalous branches of the ICA (9). Any developmental errors in the descent of heart and great vessels into superior mediastinum or failure of absorption of the third aortic arch or the upper intersegmental artery result in the elongation of the ICA (10).

Though the morphological variants of the course of the ICA are frequently defined by using different terms coiling, looping, kinking and $\mathrm{S}$ or $\mathrm{C}$ shaped elongation, tortuosity is appropriate term that can replaces others (11). Paulsen et al. (3) have classified the course of ICA into four types. According to them, if the deviation from the vertical axis is less than $15^{\circ}$, it is straight. If the deviation is greater than $15^{\circ}$ and lesser than $70^{\circ}$, then it is curved. If the deviation lies between the $90^{\circ}$ and $145^{\circ}$, then it is classified as coiled or kinked. If 
the deviation is $360^{\circ}$, it is looped. Further, they subdivided the curving into medial, lateral or ventrodorsal. In the present study, $99 \%$ of cases presented straight course, $1 \%$ of case had curved course of CCA.The middle segment of the CCA presented a lateral siphon and the convexity of the curve was directed posterior to the internal jugular vein and the vagus nerve. This siphon was situated just $2 \mathrm{~cm}$ above the origin of CCA. Unusual looping of the ICA in relation to an enlarged lymph node has been observed in a cadaver (12). Tortuosity of the ICA is rarely associated with clinical symptoms (10). The variants of the ICA may lead to degenerative alterations in the blood vessels with increase in age (3). The close relationship of the tortuous ICA with pharyngeal wall can cause difficulties in swallowing and speech and it may lead to difficulty to surgeons in this area (3). Individuals with tortuous ICA may present with focal neurological and hemispheric symptoms (3).

Though the elongation, coiling, looping or kinking of ICA is common, it is extremely rare to have these variations with respect to the ECA (13). A cadaveric case of ECA forming S shaped loop has also been reported (13). The developmental arrest in the shifting of heart and large blood vessels into the superior mediastinum or shifting of origin from the aortic sac to third aortic arch may attribute to the formation of kinks in the ECA (10). Early diagnosis of kinking of the ECA is clinically important as it is frequently associated with stenosis, vasculitis, atropic dilation and arteriosclerosis (14).

\section{Conclusion}

Anatomical knowledge of variations in the origin, course, and branching pattern of the carotid arteries will be useful in angiographic studies, transcatheter embolization procedures and in surgical procedures of the head and neck region. Though lateral curvature(looping or siphon) of the CCA is not an uncommon finding.

\section{References}

[1]. Gray H. Cardiovascular: internal carotid artery. In Gray's Anatomy (ed. Williams PL, Bannister LH, Berry MM, Collins P, Dyson M, Dussek JE et al.) 38th edn. Edinburgh: Churchill Livingstone, 1995, pp 1523-9.

[2]. Pellegrino L, Prencipe G, Vairo F. [Dolicho-arteriopathies (Kinking, Coiling, Tortuosity) of the Carotid arteries: Study by color Doppler Ultrasonography]. Minerva Cardioangiol 1998; 46(3): 69-76.

[3]. Paulsen F, Tillmann B, Christofides C, Richter W, Koebke J. Curving and looping of the internal carotid artery in relation to the pharynx: frequency, embryology and clinical implications. J Anat 2000; 197(Pt 3):373-81.

[4]. Szekely G, Csecsei GI. Anteposition of the internal carotid artery for surgical treatment of kinking. Surg Neurol 2001; 56(2): 124-6.

[5]. Perdue GD, Barreca JP, Smith RB, King OW. The significance of elongation and angulation of

[6]. the carotid artery: a negative review. Surgery 1975; 77(1): 45-52.

[7]. Ozbek C, Yetkin U, Ozelci A, Yurekli, Gürbüz A. Coiling of extracranial internal carotid artery as a cause of neurologic deficits. The Internet Journal of Thoracic and Cardiovascular Surgery 2007; 10(1): 3.

[8]. Riser M, Geraud J, Ducoudray J, ribaut L. Long internal carotid artery with vertigo syndrome. Rev Neurol (Paris) 1951; 85(2): 1457.

[9]. Sarkari NB, Holmes JM, Bickerstaff ER. Neurological manifestations associated with internal carotid loops and kinks in children. J Neurol Neurosurg Psychiat 1970; 33(2): 194-200.

[10]. Caldemeyer KS, Carrico JB, Mathews VP. The radiology and embryology of anomalous arteries of the head and neck. AJR 1998; 170(1): 197-203.

[11]. Kelly AB. Tortuosity of the internal carotid artery in relation to the pharynx. J Laryngol Otol 1925; 40:15-22.

[12]. Fazan VPS, Ribeiro RA, Oliveira MAS, Caetano AG, Rodrigues Filho OA. Tortuosity of the internal carotid artery cervical course: case reports and literature review. Braz J Morphol Sci 2007; 24(4): 244-7.

[13]. Satheesha NB. Unusual looping of the internal carotid artery in relation to an enlarged lymph node. IJAV 2010; 3: 84-5.

[14]. Vinaitha D, Anandhi KS, Saran RS, Lakshmi R, Subramaniam A. Bifurcation of the common carotid artery and looping of the external carotid artery-a case report. J Clin Diagn Res 2012; 6(3): 462-4.

[15]. Milic DJ, Jankovic MM, Zivic SS, Jankovic RJ. Coiling of the left common carotid artery as a cause of transient ischemic attacks. J Vasc Surg 2007; 45(2): 411-3 


\section{Common carotid siphon(left)}

1-common carotid siphon, 2-internal jugular vein, 3-vagus nerve
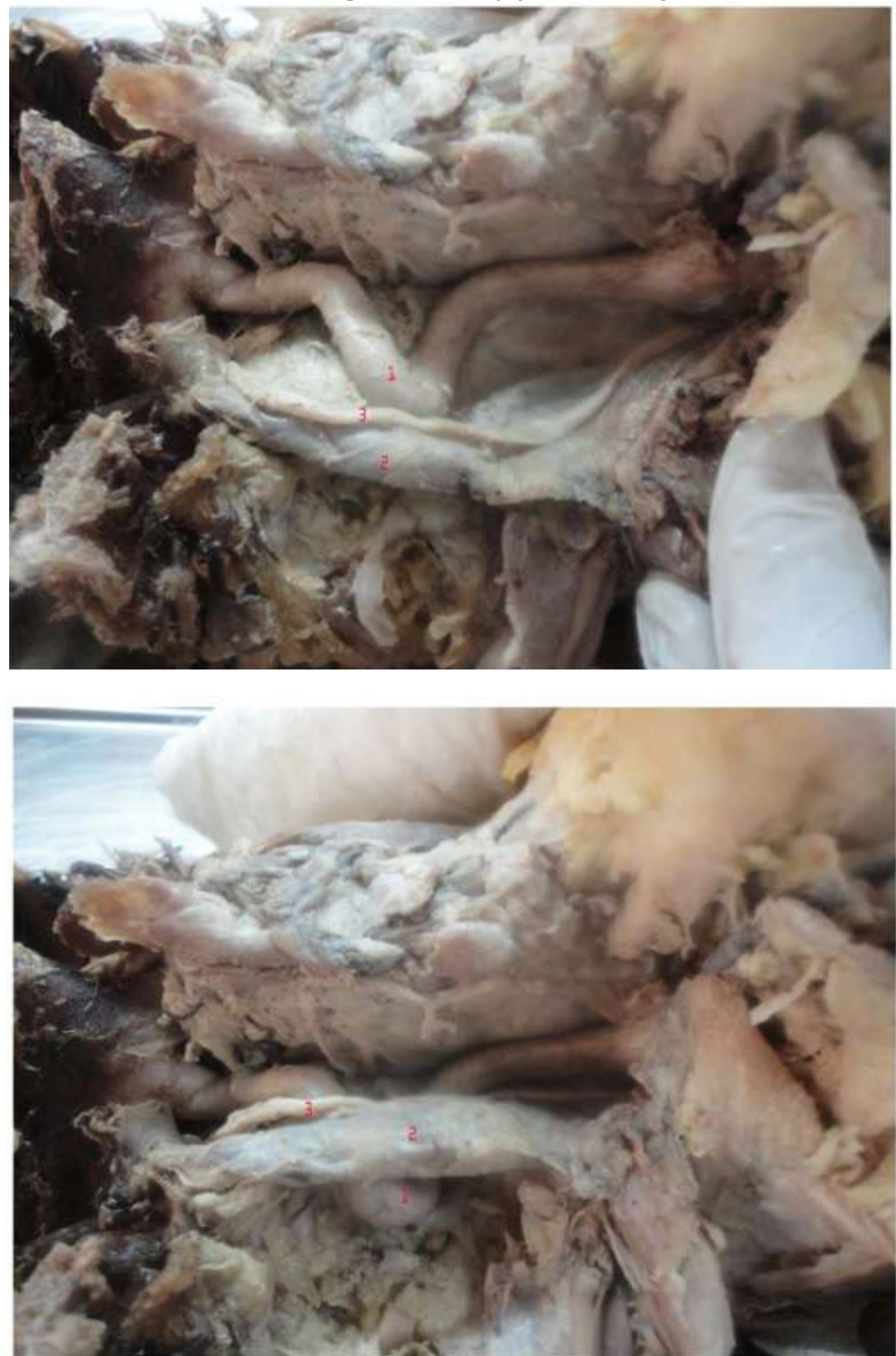